\title{
Beyond the (Dis)Empowerment Binary: Inevitability and the Feminization of Agriculture in Chitwan, Nepal
}

\section{Naomi Jade Kellogg Anton Boesgaard Andersen Rebecca Biraschi Susmita Puri}

Changing demands of the agricultural sector, due to male out-migration, have been shown to influence power dynamics and livelihood strategies within households, communities, and broader society. These shifts have led to a rise in women's agricultural engagement in Nepal. In hypothesizing the outcomes of what has been defined as the feminization of agriculture on the women left behind, the existing literature has created a (dis)empowerment binary. Based on field work conducted in Chitwan, we initially confirm that women do experience that increased agricultural engagement presents both the potential for an increased burden and an opportunity for empowerment. Our research then goes beyond this binary, by utilizing the concept of inevitability, revealing both the micro and macro level nexi of migration, agriculture, and gender in relation to the feminization of agriculture in Nepal. By underscoring the double inevitability of both male out-migration itself and women's roles within their households we argue we can more accurately represent our informants' lived realities and thereby provide an alternative to the (dis)empowerment binary for future research. This includes the recognition of a relational nature of the feminization of agriculture phenomenon, which is often overlooked in the current discourse.

Keywords: agriculture; migration; gender; inevitability; Nepal 


\section{Introduction}

Even as countries continue to transition away from agriculture-based economies, the agriculture sector remains an important means of livelihood for households in the Global South as "a fundamental instrument for sustainable development and poverty reduction" (World Bank 2007: 32). Nepal is an agricultural country characterized mostly by subsistence with semi-feudal production relations due to landholding patterns and low levels of production technology (Tamang, Paudel, and Shrestha 2014). Approximately $80 \%$ of the country's households are directly engaged in agricultural activities (Tamang, Paudel, and Shrestha 2014); however, the agriculture sector only contributes approximately $35 \%$ to the national gross domestic product (MoAD 2014: 11). As a result, thousands of Nepalis are out-migrating in search of better opportunities elsewhere (Tamang, Paudel, and Shrestha 2014). As of 2011, one in every four households in Nepal (25.42\%; 1.38 million households) reported that at least one member of their household is absent or living out of the country (CBS 2012).

Chitwan is one district of the country where out-migration outpaces national averages. In fact, approximately $30 \%$ of households in Chitwan report that at least one member of their household is absent or is living out of the country (CBS 2012). In Chitwan, migration patterns are heavily influenced by gender norms (Piotrowski, Ghimire, and Rindfuss 2013). Of the more than 50,000 locals estimated to be living outside of Chitwan, nearly nine out of ten are male (CBS 2012). Increasing numbers of men migrating away from home in search of better job prospects, has meant the women they leave behind are increasingly engaging in work that has been traditionally ascribed to men in Nepali households. Since a majority of Nepali households are engaged in agriculture, this has meant a rise in a phenomenon commonly called the feminization of agriculture (Gartaula, Niehof, and Visser 2010). Women's increased agricultural involvement is, thereby, considered to be a response to male out-migration which either acts to increase women's workload through increasing women's responsibility to ensure household survival (LastarriaCornhiel 2008), or is seen as a potential source for women's empowerment (Gartaula, Niehof, and Visser 2010: 566, Pattnaik et al. 2017). Research on the feminization of agriculture has therefore been mostly restricted to analysis which focuses on the existence, or lack thereof, of women's empowerment. This approach has effectively created a (dis)empowerment binary in the literature.

Based on data collected in 2020, this paper provides an investigation of how male out-migration is impacting women's agricultural involvement in Chitwan. We initially confirm that women do experience that increased agricultural engagement presents both the potential for an increased burden and an opportunity for empowerment. However, our research goes beyond this binary. By utilizing the concept of inevitability, we contend that the feminization of agriculture should be understood as a complex outcome impacted both by prevailing economic conditions which necessitate male out-migration in the first place, and the gendered nature of women's roles within their families' team-based livelihood strategy. By underscoring the double inevitability of both male out-migration itself and women's roles within their households, it becomes clear why male out-migration is 'accepted' as the best solution by the left behind women irrespective of the possible negative consequences male out-migration may have on their own lives. In doing so, we argue we can more accurately represent our informants' lived realities and thereby provide an alternative for future research.

This paper is divided into five sections. We first outline the existing (dis)empowerment binary discourse surrounding the feminization of agriculture. The second section outlines our methodology. In the third section, we confirm that while the impact of male out-migration on women's agricultural involvement varied amongst respondents, most households did experience a feminization of agriculture, defined as an increase in agricultural engagement after male out-migration. Next, we confirm perceptions of increased engagement as a burden and an opportunity within our data set; initially confirming existing sentiments within the literature. However, we ultimately suggest that women's increased engagement is better understood within the context of a feeling of double inevitability which reveals both the micro and macro level nexi of migration, agriculture, and gender in relation to the feminization of agriculture in Nepal.

\section{The Feminization of Agriculture}

As an increasing number of working-age men migrate abroad, the injection of massive amounts of remittance income and subsequent labor shortages have been noted as key factors in altering the physical and economic landscape in Nepal (Fox 2018). One such alteration is the feminization of the agricultural sector because of a shortage of agricultural labor which, in Nepal, is "due in particular to increased out-migration of workers and growing demand for labourers in off-farm sector employment" (Sunam and McCarthy 2016: 53). In the most literal sense, feminization of agriculture refers to an increased engagement of women in the agricultural sector (Pattnaik 
et al. 2017). This engagement includes women's work "as farmers on their own account, as unpaid workers on family farms and as paid or unpaid laborers on other farms and agricultural enterprises" (FAO 2011: 7). It also includes increasing involvement in the parma system, in which women trade their agricultural labor for the labor of others (Sunam 2020, Adhikari and Hobley 2011). Using this basic measure, Nepal has certainly seen a feminization of agriculture. The most recent Nepal Labour Force Survey shows that women now, by far, represent the majority of all agricultural employees (CBS 2019). Out of 1,523 million Nepali employed in agriculture, forestry and fishing, nearly 900,000 are females. This constitutes $33 \%$ of all employed females in Nepal. For comparison, just $14.7 \%$ (roughly 650,000) of employed men are employed in agriculture, forestry and fishing (CBS 2019).

The feminization of agriculture also refers to a broader concept that "addresses the extent to which women define, control and enact the social processes of agriculture" (Pattnaik et al. 2017: 3). It is through this more socialized definition of the feminization of agriculture that a binary discourse arises. Scholars agree that changing demands of the agricultural sector, due to male out-migration, influence power dynamics and livelihood strategies within households, communities, and broader society (Pattnaik et al. 2017). However, it is in hypothesizing the outcome of these shifts where the feminization of agriculture literature falls into two distinct camps, which ultimately create a (dis)empowerment discourse.

For some scholars, these shifts in power have led them to hypothesize that, in the long term, the feminization of agriculture due to the out-migration of men creates an opportunity for the empowerment of women in the Global South (Gartaula, Niehof, and Visser 2010, Pattnaik et al. 2017). Women's empowerment has been considered a priority of governments and development agencies for decades, and the achievement of such goals in developing countries has often been positively associated with women's involvement in the agricultural sector, building on the narrative of empowering rural women through powering agriculture (FAO 2018). While the definition of empowerment is by all accounts fuzzy, this hypothesis is grounded in the idea that an absence of males in patriarchal societal structures will ultimately lead to an expansion of women's engagement in traditionally male work both inside and outside of the home. In the Nepali context, this hypothesis is supported by literature that points out increases in Nepali women's freedom to pursue employment outside of the home and involvement in rural society after their husbands have migrated (Maharjan,
Bauer, and Knerr 2012), as well as women's increased ability to make household decisions while their husbands are away (Sunam 2020).

Other scholars point out that this view of the feminization of agriculture may actually be ignoring the reality of involvement for many women in Nepal. First, while women's agency over some decisions may increase after male out-migration, some scholars have found that due to the widespread nature of mobile phones, major household decisions are still generally made, or at least heavily influenced, by men (Adhikari and Hobley 2011). Further, without someone to help with household responsibilities, increased involvement in agricultural activity may actually mean women's workloads have simply increased. This has largely been attributed to the fact that women have the dual responsibility of both productive and reproductive work (Tamang, Paudel, and Shrestha 2014). Thereby, women may in fact be required, not allowed, to participate in agriculture as a livelihood strategy when their husbands are away. This type of involvement has been termed by Pattnaik et al. as the feminization of agrarian distress (2017), and implies a decrease in women's wellbeing, or disempowerment.

Who does, or does not, become empowered has been the subject of scholars who rightly point out that gender interacts with other axes of difference. For example, Adhikari and Hobley (2011) describe how women living in joint households with their in-laws may have less domestic burden after male-out migration since there are other adults in the household, but may also consequently have less control over household decisions since they are not the head of the household. Class differences have also been explored, with scholars pointing out that women from more well-off families are able to keep a lower physical workload by hiring outside labor to help with agricultural tasks or even renting out excess land (Karn et. al 2020, Sugden et al. 2014). This is especially true in Chitwan where, also due largely to migration and subsequent labor shortages, "the wages of male agricultural workers have increased almost five fold over the last decade from Rs 80 to Rs $400 \ldots$... [and] the wages of female agricultural workers increased from Rs 40 to Rs 200" (Adhikari and Hobley 2011: 22).

Much of the existing literature addressing the feminization of agriculture, therefore, uses methodological tools like the Women's Empowerment in Agriculture Index to place the feminization of agriculture within a (dis)empowerment binary. One of the most recent examples of this can be found in The 2018 World Bank Report, Male Out-migration 
and Women's Work and Empowerment in Agriculture: the Case of Nepal and Senegal, whose main finding acknowledged that "male-dominated outmigration may not always be associated with women's empowerment" (Kar et al. 2018: xii). Although the report does recognize that additional qualitative research is needed to better understand the contextual complexities of the issue, the paper's focus on (dis)empowerment outcomes perpetuates the notion of a (dis)empowerment binary that exists throughout the literature and broader development discourse.

Given this discourse, the question then becomes whether the (dis)empowerment binary outlined above is actually representative of women's experiences of and perceptions toward their increased agricultural engagement. Fraser Sugden, a leading geography scholar on the changing roles of rural women as they manage land and water resources in the context of migration, argued that the reality of the feminization of agriculture, especially at its nexus with male out-migration, is much more nuanced (2018). He highlights a lack of research that aims to make sense of the diverse experiences of rural women without losing sight of the intersectionality of gender with all other structural and cultural factors that impact agricultural engagement (Sugden 2018).

We situate our research within this gap in the literature by providing a better understanding of the following: How are women's roles in agriculture impacted by male out-migration? How do women in Chitwan whose agricultural involvement has increased due to male out-migration perceive their own engagement in agriculture? Finally, are these feelings limited to the (dis)empowerment binary within the current feminization of agriculture discourse which frames the phenomena as either an opportunity or a burden?

\section{Methodology}

\section{Data Collection}

Our primary data was collected during 2020 in Chitwan, Nepal. The qualitative data referenced in this report was obtained through a series of individual semi-structured interviews and corresponding field notes. Our findings are ultimately built around twenty-four semi-structured interviews with women left behind by out-migrating men, in both Nepali and Tharu languages. To protect the women's identities, we have anonymized all respondents through the use of pseudonyms. Our respondents were situated across seven different locations in Chitwan, all categorized as villages: Harnahari, Jhuani, Kathar, Kumroj, Bhokaha, Debauli and Surtana.
Our data collection occurred through snowball sampling (Groves et al. 2011), which improved our access to respondents in the rural villages we visited. This was largely due to a sense of trust that was created as each woman told the next about our project, effectively acting as spokespeople within their networks. Using this technique, our team saved time and entered each consequent interview with a foundation of trust that proved invaluable.

\section{Data Analysis}

First, we utilize interviews as phenomenological reporting (Brinkmann 2013), by using precise descriptions of what women have experienced to categorize the impact of male out-migration on each woman's agricultural involvement. This categorization illuminated the diverse experiences of women in our target group, and ultimately confirmed the existence of the feminization of agriculture (as defined as increased engagement) in our research area.

We then utilize interviews as discursive accounts (Brinkmann 2013) and build upon this categorization by examining how women talk about their changed role after male out-migration. During this phase of analysis, we utilize full transcriptions of all interviews with women whose agricultural involvement had increased after male out-migration. Through line-by-line open coding of both the full transcripts and field notes, we identified key themes, paying "particular attention to topics that the women had talked about at length, topics that they had taken up on their own initiative, and topics that seemed to engage them emotionally" (Hanh et al. 2012: 489).

\section{The Impact of Male Out-Migration on Women's Agricultural Involvement}

In utilizing our interviews as phenomenological reports, we identified three major categories of outcomes for women's agricultural involvement after male out-migration in Chitwan: (1) no/unclear change, (2) decreased involvement in agriculture and (3) increased involvement in agriculture. Increased involvement in agriculture is further broken down into three sub-categories: (3.1) increased physical involvement, (3.2) increased involvement in money management and (3.3) increased involvement in labor management. First, we conclude increased physical involvement when an interviewee describes that she is doing more physical agricultural labor now than before male out-migration. Namuna exemplifies this: "He used to bring fertilizer, seeds and water for the farm. He used to help me at the farm. And now, I am the one to bring the fertilizer, water, seeds and carry the tanks of fertilizers." Secondly, we conclude increased 
involvement in money management when our interviewees described being increasingly involved in managing finances related to agriculture, after male out-migration. Uma explains: "The responsibility has increased in terms of money management... where to use it [the money]?" Finally, we conclude increased involvement in labor management when our interviewees describe being increasingly involved in managing agricultural labor, after male out-migration. Lila explains: "When he was here, we didn't use to hire any labour at all. And she continues: "Now, we don't have time and also we can't do it physically (...), for weeding we were only two people doing it and it took days for us to finish (...), that's why we hire labour." Table 1 provides a full overview of the categorization of women's involvement in agriculture after male out-migration.

Based on this categorization, we find that most women's involvement in agriculture after male out-migration increased on at least one of our three metrics; confirming the existence of the feminization of agriculture (as defined as increased engagement) in our research area. In fact, increased agricultural involvement was most often present in at least two out of the three sub-categories simultaneously. In total, out of the sixteen interviewees with an increase in agricultural involvement after male out-migration, eleven of them fall into the sub-category of increased physical involvement, whereas six and eight fall into the

Table 1: Categorization of Women's Involvement in Agriculture After Male Out-Migration

\begin{tabular}{|c|c|c|c|c|c|}
\hline & \multicolumn{3}{|c|}{ Increased Involvement } & \multirow[t]{2}{*}{ Decreased Involvement } & \multirow[t]{2}{*}{ No Change/Unsure } \\
\hline & Labor & Money & Physical & & \\
\hline Rita & & & & & $\checkmark$ \\
\hline Gita & & & & & $\checkmark$ \\
\hline Sita & $\checkmark$ & & & & \\
\hline Anita & & $\checkmark$ & $\checkmark$ & & \\
\hline Radha & $\checkmark$ & $\checkmark$ & $\checkmark$ & & \\
\hline Gopi & & & & $\checkmark$ & \\
\hline Sapana & $\checkmark$ & & $\checkmark$ & & \\
\hline Jyoti & & & & $\checkmark$ & \\
\hline Kamala & $\checkmark$ & & $\checkmark$ & & \\
\hline Lila & $\checkmark$ & & & & \\
\hline Mohani & & & & & $\checkmark$ \\
\hline Namuna & & & $\checkmark$ & & \\
\hline Omika & & & $\checkmark$ & & \\
\hline Priya & & & $\checkmark$ & & \\
\hline Huma & & & & & $\checkmark$ \\
\hline Rojita & & & & & $\checkmark$ \\
\hline Sarita & & $\checkmark$ & & & \\
\hline Deepa & & $\checkmark$ & & & \\
\hline Uma & $\checkmark$ & $\checkmark$ & $\checkmark$ & & \\
\hline Sandhya & $\checkmark$ & & & & \\
\hline Pema & & $\checkmark$ & $\checkmark$ & & \\
\hline Bishnu & $\checkmark$ & & $\checkmark$ & & \\
\hline Rupa & & & $\checkmark$ & & \\
\hline Rama & & & & $\checkmark$ & \\
\hline Total & 8 & 6 & 11 & 3 & 5 \\
\hline
\end{tabular}


subcategories of, respectively, increased money and labor management.

\section{Burden or Opportunity?}

The categorization above outlined the dynamics of feminization of agriculture as increased engagement in Chitwan. However, an analysis limited to the categorization of the outcomes of male out-migration on women's agricultural involvement does not create the space required to discuss the broader perceptions of these women's social realities. The following paragraphs zoom in on those cases where we identify increased involvement in agriculture, and ask how women in Chitwan, whose agricultural involvement has increased due to male out-migration, perceive their own engagement in agriculture. In this section, we provide an initial confirmation within our data of the (dis)empowerment binary that is found in the existing literature by presenting the ways in which our informants perceived their increased agricultural engagement as a burden or an opportunity.

Increased Engagement as a Burden

When discussing their increased agricultural engagement, our informants often described their increase in engagement as a burden. With their male counterparts absent, the women spoke of having no one to share the burden with, which ultimately fueled a feeling of being overwhelmed. But it is not just that "women in migrant households in Nepal are more overworked" (Kar et al. 2018: 26), it is that they feel an emotional burden of being more responsible. When asked how this made her feel, Namuna shared: "Sometimes I feel sad. If my husband was here, we could share the burden [together]."

This burden was often also framed within a wider context of women's perceived societal roles. In the villages we visited, women's traditional roles as caretakers and homemakers did not simply change once their husbands migrated. Increased engagement in agriculture often came in addition to prior responsibility, not in place of. This echoes the sentiment of Tamang et al., who recognize that a dual burden of being responsible for both productive and reproductive work makes women's lives more difficult (2014). The sheer amount of responsibility many of our informants shouldered was startling, and was often accompanied by feelings of stress, as Bishnu shared: "Yes, all the responsibilities are on me...if there's anything to do then it's on me, sometimes I get headaches...sometimes I get headaches thinking about them. It's a tension for me."

Household composition seemed to play an important role in understanding the nature of the engagement described by many of our informants. For example, women like Kamala, who live in nuclear households, and therefore do not have other adult family members at home with which to share the workload, seemed especially impacted. When asked how she felt about having the sole responsibility in the household now that her husband has migrated, she shared the following: "We [women] are working, doing everything like looking after the fields, agriculture, taking care of the children, looking after the house and everything, buying supplies, cooking and feeding and eating: How much work is that?! Isn't it more work than [our migrated husbands']?!"

Household composition was also relevant in terms of the age of each woman's children. The nature of doing agricultural work as a mother of young children often presented additional unique challenges for the women. Our informants told us stories of how they balanced the demands of breastfeeding and duties in the fields by making several trips back home throughout the day. This strategy ultimately frustrated them, as the time spent traveling to and from home negatively impacted their daily productivity. Alternatively, women simply brought their children along or were forced to adjust their agricultural schedules around when they could find (and afford) childcare.

Even in describing their increased workload as burdensome, we did not find clear indications of the types of diminishing wellbeing that would lead us to conclude that any of our informants perceived their situations as what Pattnaik et al. term 'feminization of agrarian distress' (2017). Instead, women openly shared the difficulties they faced in their new realities. While some may have more explicitly outlined the stresses of their new arrangements than others, all acknowledged the challenges of balancing the work they are expected to do as both farmers, wives, and mothers.

\section{Increased Engagement as an Opportunity}

In line with the more positive development discourse developed by the existing literature suggesting feminization of agriculture may lead to empowerment (Gartaula et al. 2010, Maharjan et al. 2012, Sahed, Flora, and Islam 2017), respondents also spoke of their increased engagement in agriculture as an opportunity. This opportunity was framed by our respondents in three ways: opportunity to contribute to family livelihood, opportunity to acquire new skills, and opportunity to challenge socio-cultural expectations of women.

In some of the respondents' experience, increased involvement in agriculture is an opportunity to achieve better 
living conditions in their households in a joint effort with their out-migrated husbands. For example, male out-migration 䤁 often acted as a tool for increasing a household's access to land by providing a family with the income required to purchase land. Existing literature regarding land access suggests that landownership and landholding influences families' social, economic, and political power (Sijapati, Lama, Baniya, Rinck, Jha, and Gurung 2017). The women we spoke with, perceived land ownership as a prestige, a tool for social acceptance (Berger 1988), and as a means for securing food (Tamang et al. 2014). By accessing land, increased engagement in agriculture is an opportunity for women to contribute to their household's livelihood strategy. In this regard, Omika described: "I am working hard. It has definitely changed from how it used to be before. It was difficult for us to afford food and clothes back then. But now both of us are working hard. We are able to give our children a better education. The money that we earn [from agriculture and remittances]... is being used to build our house. Our old house was very bad. Now we have a concrete house, which is much better."

Women's increased agricultural engagement ultimately also provided women with another opportunity: guarding their families against the uncertainty of remittance inflows. In particular, some of the respondents claim that there is a certain degree of unpredictability related to the time at which money will be sent home by their husbands. Therefore, agriculture represents an alternative source of livelihood for families that cannot rely on punctual remittances. In the uncertainty of when remittances will reach home, Pema proudly told our team: "I am the one taking care of our family and making things work here."

Increased agricultural engagement was also described as an opportunity for women to learn new skills. As part of their new responsibility, respondents were often required to learn new skills to perform the agricultural tasks that had been completed by their husbands or sons before migration. In this context, increased agricultural involvement is experienced by some women as a means of fostering self-development (Kaspar 2005). In this regard, Uma refers to her husband's migration and her increased engagement in agriculture claiming that: "It has also allowed me to learn more. It is an opportunity to learn more things. I did not know how to do all those things previously but now I know how to do those on my own (...) I am confident because of the learning opportunity I am getting at present."

For some women, feelings toward increased engagement as an opportunity to acquire new skills has also fostered feelings of self-confidence and awareness of their abilities (Kaspar 2005 in Gartaula et al. 2010). In this way, increased engagement is seen as an opportunity to challenge existing expectations of women. These feelings must be understood in the socio-cultural context of Nepali agricultural work, in which there is a specific division of labor tasks between men and women, with men traditionally being in charge of performing the more physically intensive agricultural work (Pokharel 2011). With men out of the picture, women who can afford labor have become involved in labor management decisions previously reserved to their male household heads. Meanwhile, women who cannot afford to hire labor, like Anita, have adapted and broken out of traditional gendered agricultural roles by performing the traditionally male tasks themselves: "Looking at that stage of my life ... I have been able to do things better than I could have done. (...) Now I know everything [about farming]. (...) Even if I cannot work like a man I can still do things on my own." It is within this context that we saw what most resembles empowerment - women smiling with pride when realizing all they had been able to manage on their own.

\section{The Feminization of Agriculture Beyond the Binary}

After initial confirmation of the existence of what could be described as perceptions of both empowerment and disempowerment amongst our informants, we recognized an even more pressing theme that stretched the entirety of our data. It seems that regardless of the burden or opportunities they felt their husband's or son's migration brought, the resulting positive or negative outcomes were seen as inevitable. Indeed, it seems that women left-behind perceive themselves in a seemingly no-choice situation in which they are suddenly fully in charge of managing their households and engaging in agriculture to sustain their families. Many, like Bishnu, even went as far as to describe this inevitability as the common condition: “(...) we [women] have to do it because it's on us... if we don't [feel happy with all the workload] we have to feel good about it... what else can we do?! If we say we don't feel happy with it then who is going to do all this work... we have to do it too... we are alone so it's our duty to do it."

Other informants echoed this mentality, often also shrugging off or laughing at questions about how their new realities made them feel. For our informants, reflecting on their own perceptions often seemed foolish. We were often met with statements of confusion and follow up questions like, "What do you mean?" and "Why would that matter?" - this is just the way it is. 
By employing the concept of inevitability in regard to our informants' discourse around the feminization of agriculture, we present a clearer overview of our informants' lived realities than the existing literature's binary (dis) empowerment approach. We argue that the feminization of agricultural phenomena should not be understood solely as a (dis)empowerment binary of burden or opportunity, but rather as a complex outcome at the nexus of migration, agriculture and gender at the macro and micro scales. The application of the concept of inevitability aids in explaining why male out-migration is 'accepted' as the best solution by the left-behind women despite its possible negative consequences for themselves. This acceptance is based on a double inevitability, in which the increased agricultural engagement of women is perceived as an inevitable outcome of inevitable male out-migration, and holds across our respondents, even though their individual experiences of inevitability may vary. In doing so, we combine the diverse experiences of individual women with the broader socio-economic context in which the feminization of agriculture exists, as Sugden (2018) calls for, to highlight the intersectionality of the feminization of agriculture in at least two ways.

First, an understanding of inevitability highlights the fact that the feminization of agriculture exists at a macro level nexus with migration. In that relation, we suggest that prevailing socio-economic conditions in Chitwan promote a discourse of male out-migration itself as inevitable amongst the women who are left behind. Male out-migration is pursued as a main livelihood strategy by an increasing number of rural households in Nepal (Bhawana and Race 2019), due to a variety of socio-economic factors, such as weak financial conditions, lack of employment opportunities, low education rates, structural inequalities, and the prospect of better economic opportunities (Jaquet, Kohler, and Schwilch 2019). Sunam (2020) even calls the phenomenon ubiquitous. He points out that the phenomenon includes people from all castes, settings, and classes - with "even youth from well-off households [indicating] that migration has become an undeniable option for them" (Sunam 2020: 91).

Most interviewees talked about the hardship related to their engagement in agriculture as well as to their husbands' migration as the only available option to grant a better livelihood to their families. Once again referring to male out-migration as a main livelihood strategy of rural households, we suggest that the left-behind women should not necessarily be seen as victims. Instead, their changed roles are understood as a logical consequence, independent of the binary distinction between burden and opportunity. For instance, when asked whether she prefers to have less work and responsibilities with her husband at home, or more work and responsibilities with husband abroad and more money, Bishnu replied: "I feel it's a lot of responsibility [to handle everything on my own], but I can't choose between them, because you need money too."

Further, Bohra and Massey (2009) find that out-migration from Chitwan is more likely for individuals with connections to neighbors with experiences of migration, creating a snowball effect as more men out-migrate. This was evident in conversations with our informants who increasingly felt that avoiding male out-migration while simultaneously improving family livelihood is entirely unrealistic. Radha made this clear, raising her voice and directly addressing the inevitability of male out-migration for her family's livelihood: "Yes, if he didn't go abroad then how would we have educated our children?! How would we have raised them?!" Therefore, as male out-migration itself becomes more prominent we suggest that women's increased engagement in agriculture, in Chitwan, is perceived as the logical consequence of what is perceived by the women themselves as inevitable male out-migration.

Secondly, at the micro scale, centering inevitability presents a clear window into why women in Chitwan do not question their increased engagement in agriculture at the household level after male out-migration, despite our findings that it may be perceived as a burden. In the context of Nepali patriarchal society, women's role as 'homemakers' entails their engagement in household chores (Langer et al. 2019) as well as socio-cultural expectations of women as caretakers for their children (Care 2015). These socio-cultural expectations foster in women a sense of duty and commitment towards their children, as expressed by most of our interviewees. In this regard, Anita claimed: "I am doing all my hard work on my own. My children encourage me to work harder. Looking at their faces makes me want to do things that I couldn't do before. No matter if we had less or more money, I would do the work for my children."

In fact, the desire to provide children with a promising life perspective, with a particular reference to education, represents one of the principal reasons behind women's commitment to agriculture.

In the presence of male out-migration, feelings of duty to take care of their children often translate into women increasingly bearing the responsibilities towards their households, which necessarily results in women's increased engagement in agriculture when men 
out-migrate (Kelker 2009 in Aryal and Kattel 2019). We found this to be particularly relevant in households which lacked the presence of extended family. This is largely due to the fact that, as other studies have found, "the effects of male out-migration on women's participation in agricultural work and decision-making are contingent upon the domestic arrangement in which they are part" (Gartaula et al. 2010: 575). Women living in larger households and/ or with in-laws, or other able-bodied male relatives, often saw their agricultural roles stay the same or even decrease after male out-migration since these women did not become pseudo household heads.

Women's increased agricultural engagement, or lack thereof, is therefore not a haphazard coincidence. But rather, an intentional decision and vital part of each family's livelihood strategy. Husbands working and living abroad provided essential financial support to their families through remittances, whose use to improve the household's living conditions is a top priority (Khanal, Alam, Khanai, and Regmi 2015). The best chances of which, at least in the Tarai Region of Nepal, seem to be through the combination of both migration and farming (Sunam 2015). Consequently, the women that are left behind play their own essential roles as caretakers of both children and the family's agricultural involvement. This relational component, which highlights each family's sense of teamwork, provides further clarity as to why even when women's increased agricultural engagement fits in the 'increased engagement as a burden' literature discourse (Tamang et al. 2014), respondents perceive increased engagement in agriculture as non-questionable, insofar inevitable. In this way, existing gender norms that cast women as the caretakers in their households result in their own feelings of inevitability towards their increase in agricultural engagement, and are compounded by the familial sense of teamwork required to secure household livelihood.

\section{Concluding Remarks \& Areas for Further Research}

The fifth Sustainable Development Goal (SDG) is to achieve gender equality and empower all women and girls, and recognizes the importance of eliminating all forms of discrimination and ensuring women's full and effective participation and equal opportunities for leadership at all levels of decision-making (UN 2020). The feminization of agriculture due to male out-migration has been framed by some scholars as a possible mechanism for women's empowerment in the Global South. As male out-migration continues in Nepal, the need for qualitative context of the feminization of agriculture becomes more pressing.
Reports like the World Bank's 2018 Male Out-migration and Women's Work and Empowerment in Agriculture: The Case of Nepal and Senegal (Kar et al. 2018) at least acknowledge the diversity of outcomes of the feminization of agriculture and call for additional research. However, reports like these still perpetuate the idea of a (dis)empowerment binary that persists throughout the existing literature.

With this in mind, our findings add to the literature using data collected during a 2020 field study in Chitwan, Nepal, to investigate the impact of male out migration on women's agricultural engagement. Aligning with the existing literature, our data shows that the changes women experienced in their agricultural involvement after male out-migration are extremely diverse. While most women did report an increase in agricultural engagement after male out-migration, this engagement existed through different combinations of increases in physical labor, labor management, and money management. Notably, in most cases of increased engagement, at least two out of the three sub-categories were present. The nature of these changes seems to be largely influenced by both household composition (i.e. the presence of small children or living with extended family) and access to land. In analyzing how women discussed their increased involvement we found that our informants perceived their new roles as an increased burden or increased opportunity. However, unlike much of the existing literature, we found that these feelings often coexisted, instead of being mutually exclusive perceptions about increased engagement.

By utilizing the concept of double inevitability, we argue that we can better understand both the diverse experiences of individual women and the broader socio-economic context in which the feminization of agriculture exists. In doing so, we have highlighted the ways in which prevailing socio-economic conditions in Chitwan promote a discourse of male out-migration itself as inevitable, which has led to the changed roles for left-behind women to be viewed as a logical consequence. Similarly, it becomes clear why women in Chitwan do not question their increased engagement in agriculture at the household level after male out-migration independent of the binary distinction between the feminization of agriculture as either a burden or an opportunity.

To best understand the impacts of the feminization of agriculture in Nepal we need to go beyond the (dis)empowerment binary. While centering the voices and individual experiences of women is essential, we cannot lose sight of the socio-economic context in which their experiences exist. By utilizing the concept of double inevitability to 
At time of writing, all authors were master's students at the University of Copenhagen, Denmark pursuing MSc's in Global Development. Naomi Jade Kellogg is a former Fulbright Grantee and alumni of the School of Public and Environmental Affairs at Indiana University, USA. Rebecca Biraschi is an alumni of the Global Governance B.A. program at the University of Rome Tor Vergata, Italy. Anton Boesgaard Andersen holds a Bachelor of Science in International Studies and Geography from Roskilde University, Denmark. Susmita Puri holds a Bachelor of Development studies from Kathmandu University, Nepal.

The authors wish to express their deep gratitude to all the women of Chitwan that welcomed us into their homes and shared their stories, without which this research could not have been realized. The authors also wish to express great appreciation for Assistant Professor Rune Bolding Bennike's valuable and constructive guidance throughout the research. Finally, we would like to offer special thanks to our research assistant Alisha Chaudhary. We are deeply grateful for her essential contribution, tireless commitment, and unbounded optimism during our time in the field.

understand both the macro and micro level nexi of migration, agriculture and gender, we can do just that. This understanding of double inevitability also calls into question whether existing feminization literature tends to downplay the relational aspects of male out-migration. In fact, by applying the concept of inevitability to the feminization of agriculture, it becomes clear that attempts to frame the feminization of agriculture phenomenon solely at the individual level ignore the strong sense of familial teamwork that impacts the nature of women's engagement in agricultural work. With this in mind, further research focused on this relational nature may be the key to understanding why certain outcomes of (dis)empowerment are more likely in different household compositions and hold predictive power that can help development professionals ensure women's post-migration agricultural involvement is more opportunity, than burden.

\section{References}

Adhikari, Jagannath, and Mark Hobley. 2011. "Everyone is Leaving-Who Will Sow our Fields? The Effects of Migration from Khotang District to the Gulf and Malaysia." Swiss Agency for Development and Cooperation and Helvetas: Kathmandu.

Aryal, Urmila, and Rishi Ram Kattel. 2019. “Drudgery Reduction for Women in Agriculture Sector in Nepal: An
Analytical Study." Archives of Agriculture and Environmental Science 4(4): 449-463.

Bhawana, KC and Digby Race. 2019. "Outmigration and Land-Use Change: A Case Study from the Middle Hills of Nepal." Land 9(1):1-19.

Brinkmann, Svend. 2013. Qualitative Interviewing. Oxford University Press.

Berger, Erling. 1988. Non-Monetary Aspect of Values in Land. Oslo: Institutt for Sosialforskning (INAS).

Bohra, Pratikshya, and Douglas S. Massey. 2009. "Processes of Internal and International Migration from Chitwan, Nepal." International Migration Review 43(3): 621-651.

Care. 2015. "Nepal - Gender Relations in Nepal Overview." ReliefWeb. Accessed 11 October 2020. https://reliefweb. int/sites/reliefweb.int/files/resources/RGA\%20 Overview\%20Nepal_Final\%20\%281\%29.pdf

Central Bureau of Statistics (CBS). 2012. "National Population and Housing Census 2011 (National report). Vol. 01." National Report. Nepal: National Planning Commission Secretariat - Government of Nepal.

2019. "Nepal Labour Force Survey, 2017/18." Household Surveys. Nepal: National Planning Commission Government of Nepal.

Food and Agriculture Organization (FAO). 2011. The State of Food and Agriculture 2010-2011: Women in Agriculture - Closing the Gender Gap for Development.

\section{- 2018. Empowering Rural Women, Powering Agriculture -- Fao's Work on Gender.}

Fox, Jefferson. 2018. “Community Forestry, Labor Migration and Agrarian Change in a Nepali Village: 1980 to 2010." The Journal of Peasant Studies 45: 610-629.

Gartaula, Hom Nath, Anke Niehof, and Leontine Visser. 2010. "Feminisation of Agriculture as an Effect of Male Out -migration: Unexpected Outcomes from Jhapa District, Eastern Nepal." The International Journal of Interdisciplinary Social Sciences 5(2): 565-577.

Groves, Robert M., Floyd J. Fowler Jr, Mick P. Couper, James M. Lepkowski, Eleanor Singer, and Roger Tourangeau. 2011. Survey Methodology. New Jersey: John Wiley \& Sons Inc.

Hanh, Nguyễn Thị Thúy, Vibeke Rasch, Bùi Kim Chi, and Tine Gammeltoft. 2012. "Prevention of Mother-to-Child Transmission-Precarious Hopes and Childbearing Choices Among HIV-Infected Women in a Northern Province of Vietnam.” Women \& Health 52(5): 485-502. 
Jaquet, Stéphanie, Thomas Kohler, and Gudrun Schwilch. 2019. "Labour Migration in the Middle Hills of Nepal: Consequences on Land Management Strategies." Sustainability 11(5): 1349.

Kar, Anuja, Vanya Slavchevska, Victoria Stanley, Robert Townsend, Sanna Lisa Taivalmaa, Riccardo Ciacci, Susan Kaaria, Erdgin Mane, and Yurie Tanimichi Hoberg. 2018. "Male Out Migration and Women's Work and Empowerment in Agriculture: The Case of Nepal and Senegal." The World Bank. No. 127755: 1-88.

Kaspar, Heidi. 2005. "I am the Household Head Now!" Gender Aspects of Out-Migration for Labour in Nepal. Kathmandu: Nepal Institute of Development Studies (NIDS)

Khanal, Uttam, Khorshed Alam, Ramesh C. Khanal, and Punya P. Regmi. 2015. "Implications of Out-migration in Rural Agriculture: A Case Study of Manapang village, Tanahun, Nepal." The Journal of Developing Areas 49: 331-352.

Langer, Julia A., Julia V. Ramos, Lajina Ghimire, Sauharda Rai, Brandon A. Kohrt, and Matthew D. Burkey. 2019. "Gender and Child Behavior Problems in Rural Nepal: Differential Expectations and Responses." Scientific Reports 9(1): 1-10.

Lastarria-Cornhiel, Susana. 2008. "Feminisation of Agriculture: Trends and Driving Forces." World Development Report Background Papers. Washington DC: The World Bank.

Lund, Christian. 2014. The Ethics of Fruitful Misunderstanding. Journal of Research Practice, 10(2): N4-N4.

Maharjan, Amina, Siegfried Bauer, and Beatrice Knerr. 2012. "Do Rural Women Who Stay Behind Benefit from Male Out-Migration? A Case Study in the Hills of Nepal." Gender, Technology and Development 16(1): 95-123.

Ministry of Agricultural Development (MoAD). 2014. Statistical Information on Nepalese Agriculture (2013/2014). Ministry of Agricultural Development, Government of Nepal.

Pattnaik, Itishree, Kuntala Lahiri-Dutt, Stewart Lockie, and Bill Pritchard. 2017. "The Feminization of Agriculture or the Feminization of Agrarian Distress? Tracking the Trajectory of Women in Agriculture in India." Journal of the Asia Pacific Economy 23(1): 138-155.

Piotrowski, Martin, Dirgha Ghimire, and Ronald Rindfuss. 2013. "Farming Systems and Rural Out-Migration in Nang Rong, Thailand, and Chitwan Valley, Nepal." Rural sociology 78(1): 75-108.
Pokharel, Binod. 2001. "Gender Roles and Activities Among the Rural Poor Households: Case Studies from Hill Villages." Occasional Papers in Sociology and Anthropology 7: 65-82.

Sahed, Khan, Begum Flora, and M. M. Islam. 2017. “A review on feminization of agriculture and women empowerment in Bangladesh." Fundamental and Applied Agriculture 2(1): 183-188.

Sijapati, Bandita, Ang Sanu Lama, Jeevan Baniya, Jacob Rinck, Kalpana Jha, and Amrita Gurung. 2017. "Labour Migration and the Remittance Economy: The Sociopolitical Impact." The Centre for the Study of Labour and Mobility. Kathmandu: Social Science Baha.

Sugden, Fraser. 2018. "Feminization of Agriculture Opportunity or Burden? Polarized Lessons from Nepal." Thrive Blog. Accessed 11 October 2020. https://wle.cgiar. org/thrive/big-questions/what-truth/feminizationagriculture

Sugden, Fraser, Niki Maskey, Floriane Clement, Vidya Ramesh, Anil Philip, and Ashok Rai. 2014. "Agrarian Stress and Climate Change in the Eastern Gangetic Plains: Gendered Vulnerability in a Stratified Social Formation." Global Environmental Change 29: 258-269.

Sunam, Ramesh. 2015. "The Significance of Foreign Labour Migration and Land for Poverty reduction in Nepal. Poverty Reduction Policies and Practices in Developing Asia." Springer. Singapore.

_. 2020. "Transnational Labour Migration, Livelihoods and Agrarian Change in Nepal: The Remittance Village," Routledge.

Sunam, Ramesh, John F. McCarthy. 2016. "Reconsidering the links between poverty, international labour migration, and agrarian change: critical insights from Nepal." The Journal of Peasant Studies 43(1): 39-63.

Tamang, Sujata, Krishna P. Paudel, and Krishna K. Shrestha. 2014. "Feminization of Agriculture and its Implications for Food Security in Rural Nepal." Journal of Forest and Livelihood 12(1): 20-32.

United Nations (UN). 2020. "Goal 5: Achieve gender equality and empower all women and girls." Sustainable Development Goals. https://www.un.org/ sustainabledevelopment/gender-equality/

World Bank. 2007. "World Development Report 2008: Agriculture for Development.” World Development Report. Washington DC: The World Bank. 